\title{
INVESTIGATION OF THE EFFECT OF PARTICLE SIZE ON GROUNDNUT-OIL SOLVENT EXTRACTION
}

\author{
S.V. Manyele* and I.F. Kahemela \\ Chemical and Process Engineering Department, University of Dar es Salaam, \\ P.O. Box 35131, Dar es Salaam, Tanzania
}

\begin{abstract}
An investigation of the effect of particle size on the performance of vegetable oil recovery by solvent extraction is reported. Experiments were conducted using soxhlet extractor, groundnuts and n-hexane. Samples were grouped into mean particle sizes of 0.25, 0.75, 1.3, 3.3, and $7.5 \mathrm{~mm}$ using standard sieves. The effect of particle size was studied for extraction time intervals of 1, 2, 3, 4, 5 and 8 hours. The oil yield, oil recovered per $\mathrm{kg}$ solvent used, $\mathrm{kg}$ solvent lost per unit time, and the rate of extraction $(\mathrm{kg}$ oil recovered per hour) decreased with increasing particle size. Meanwhile, the percent of solvent recovered, the ratio of oil recovered to the total volatile matter driven off and the $\mathrm{kg}$ solvent lost per $\mathrm{kg}$ oil recovered, increased with increasing particle size. Based on the normalization of averaged extraction-parameters, a mean particle size of $3.3 \mathrm{~mm}$ was observed to be the optimum size.
\end{abstract}

Keywords: Solvent extraction, oilseeds, groundnuts, oils, particle size, solvent loss, extraction time.

\section{Introduction}

Vegetable oil processing industry involves the extraction and processing of oils and fats from vegetable sources like oil seed, fruits and nuts. Most used oilseeds include sunflower, soybean, groundnuts, coconut, palm, cottonseed, olive, corn, rapeseed, and many others. Seeds (like soybeans) with low oil content, about 16\% (Ratledge and Boulton, 1985), are processed by solvent extraction methods alone different from groundnuts with higher oil content of 30\% (Misra and Yaday, 1997; Ratledge and Boulton, 1985). In other cases, presses are used first to extract part of the oil; then solvents are used to extract the oil that remains in the seeds. This paper is focused on the solvent extraction of oil from groundnuts, principally used for human consumption, medicinal purposes, etc. (World Bank, 1998; FAO, 1990; WHO, 1973).

The properties of the groundnut oil ( $\mathrm{Cobb}$ and Johnson, 1973) include low melting point, $\left(0-3^{\circ} \mathrm{C}\right)$, saponification value (188-195), free fatty acids $(0.02-0.6 \%)$, density of 0.91 at $25^{\circ} \mathrm{C}$, mean viscosity of $71-86 \mathrm{cP}$ at $20^{\circ} \mathrm{C}$, with a light yellow color.

The main components of vegetable oils are neutral triacylglycerols (Rodrigues et al., 2005), predominantly unsaturated light fatty acids of two kinds: monounsaturated (oleic acid, C8:1; 282 $\mathrm{g} / \mathrm{mol}$ ) and polyunsaturated (linoleic and linolenic acids) (Rodrigues et al., 2005; Assunçäo et al., 1984; Elias and Bressan, 1961). Fatty acid composition of groundnuts shows that the oleic $(\mathrm{O})$ to linoleic acid $(\mathrm{L})$ ratio $(\mathrm{O}: \mathrm{L})$ varied between 0.91 and 1.23 among various cultivars and is an indicator of oil stability (Jambunathan, 1991). Because most press or expeller processes leave too much of the high value oil in the seed cakes, methods of extracting the oil with solvents have been developed (Rivera and Migiro, 1990).

According to Reddy (1988), the groundnut oil cake comprise of moisture (8-10\%), oil (0.7-6\%) crude protein $(45-60 \%)$, carbohydrates $(22-30 \%)$, mineral matter $(4-5.7 \%)$ and crude fiber $(3.8-7.5 \%)$, which makes it a suitable feedstuff. Thus, up to $6 \%$ of the oil remains in the cake. It is possible to recover these losses using solvent extraction which can reduce the residual oil in cake to less than $1 \%$.

Solvent extraction is basically a mass transfer operation involving diffusion of a suitable solvent into oil-bearing cells of the raw material, resulting in oil-solvent solution (miscella). The oil is then distilled and the solvent evaporated leaving the oil behind. This process leaves minimum oil residual in the cake compared to mechanical means (Rivera and Migiro, 1990). Early work indicated that the rate-controlling factor in the solvent extraction of seeds was the internal resistance of the particles or flakes to the molecular diffusion of the solvent-oil mixture (Boucher et al., 1942). The solvent extraction process is determined by the rate at which equilibrium is attained between lean miscella outside the seed particles and oil and solvent within the particles.

The process is less expensive than competitive physical or chemical method and useful where large quantities of seed can be processed, at least 200 
tons per day (US-EPA, 2001a), although larger plants $^{1}$ with capacities of up to 4,000 tons per day exist (US-EPA, 2001a). Solvent loss during extraction, expressed as loss factors, is another factor which must be considered (US-EPA, 2001a; 2001b). Drawbacks of solvent extraction include high investment costs, the need for highly skilled labour, low employment generation and danger of explosion if the plant is not kept in safe and perfect conditions.

Modern methods of oil recovery include size reduction and pressing, followed by dissolving the crop in a solvent, most commonly n-hexane (Rivera and Migiro, 1990). The increased oil content in the solvent during reuse affects the performance due to equilibrium phenomena.

Various solvents can be used for extraction (e.g., n-heaxane, benzene, toluene, petroleum ether, diethyl ether, etc.), properties of which are listed in Table 1. n-Hexane is the most used
The focus of this study is the effect of particle size of ground seeds on the solvent extraction performance. Particle size variations occur during size reduction which incorporates either crushing or grinding of dried groundnut seeds. Small size of seed particles will facilitate solvent extraction by reducing the distances that solvent and oil must diffuse in and out of the seed particle during the extraction process. The smaller the particle size, the greater is the interfacial area between the solid and solvent and therefore the higher is the rate of transfer of the oil and solvent outside the seed particles.

\section{Modeling of solvent extraction}

The factors affecting the yield of the process include size of the particles, $d_{p}$ (determined by size reduction operation prior to extraction), moisture content, determined by the extent of drying of the sample; extraction time, starting from the initial boiling of the solvent and temperature, determined by the boiling point of the solvent.

Table 1: Properties of common solvents used for solvent extraction

\begin{tabular}{|l|l|c|c|c|}
\hline Solvent & Chemical Formula & $\begin{array}{c}\text { Boiling } \\
\text { point }\end{array}$ & $\begin{array}{c}\text { Dielectric } \\
\text { constant }\end{array}$ & $\begin{array}{c}\text { Density } \\
\text { (g/ml) }\end{array}$ \\
\hline n-Hexane & $\mathrm{CH}_{3}-\mathrm{CH}_{2}-\mathrm{CH}_{2}-\mathrm{CH}_{2}-\mathrm{CH}_{2}-\mathrm{CH}_{3}$ & $69^{\circ} \mathrm{C}$ & 2 & 0.655 \\
\hline Benzene & $\mathrm{C}_{6} \mathrm{H}_{6}$ & $80^{\circ} \mathrm{C}$ & 2.3 & 0.879 \\
\hline Toluene & $\mathrm{C}_{6} \mathrm{H}_{5}-\mathrm{CH}_{3}$ & $111^{\circ} \mathrm{C}$ & 2.4 & 0.867 \\
\hline Diethyl ether & $\mathrm{CH}_{3} \mathrm{CH}_{2}-\mathrm{O}-\mathrm{CH}_{2}-\mathrm{CH}_{3}$ & $35^{\circ} \mathrm{C}$ & 4.3 & 0.713 \\
\hline Chloroform & $\mathrm{CHCl}_{3}$ & $61^{\circ} \mathrm{C}$ & 4.8 & 1.498 \\
\hline Ethyl acetate & $\mathrm{CH}_{3}-\mathrm{C}(=\mathrm{O})-\mathrm{O}-\mathrm{CH}_{2}-\mathrm{CH}_{3}$ & $77^{\circ} \mathrm{C}$ & 6 & 0.894 \\
\hline Dichloromethane & $\mathrm{CH}_{2} \mathrm{Cl}$ & $40^{\circ} \mathrm{C}$ & 9.1 & 1.326 \\
\hline
\end{tabular}

solvent for this purpose whose residue in the oil must be kept below $150 \mathrm{ng} / \mathrm{m}^{3}$ (World Bank, 1998). The low boiling point of n-heaxane $\left(67^{\circ} \mathrm{C}\right)$ and the high solubility of oils and fats in it (Rivera and Migiro, 1990) are the properties exploited in food processing. N-Hexane was selected in this study due to its low viscosity, high volatility, simple structure and percentage of saturation, etc. Other factors such as economics, edibility of the products obtained from extraction, high solvency, low boiling point, low toxicity, and low cost were also considered (Rivera and Migiro, 1990).

\footnotetext{
${ }^{1} \mathrm{http}:$ \lunderstanding solvent extraction of vegetable oils.htm
}

\section{Moisture content}

This factor was controlled by prolonged drying of the seeds before applying size-reduction operation. The seeds were dried in the oven set at $105 \pm 5^{\circ} \mathrm{C}$ for 48 hours to eliminate the moisture.

\section{Mean particle size}

The mean particle size is given as the mean size of the sieves between which the particles are trapped, that is:

$$
d_{p}=\frac{d_{p, \max }+d_{p, \min }}{2}
$$

This factor was controlled by size reduction operations of ground nut seeds prior to extraction. Standard sieves were used to distribute the particles into different size groups. Five different sieve sizes 
were used in this study, giving the following mean particle sizes: $0.25,0.75,1.3,3.3$, and $7.5 \mathrm{~mm}$.

\section{Extraction time}

Also called contact time, was controlled by measuring the time from the observation of first drop of the solvent from the condenser. Extraction time intervals were varied between 1 and 8 hours, by stopping the extraction process exactly after a selected time interval.

\section{Extraction temperature}

This factor is difficult to control, except by fixing the rate of heat input to the flask containing the solvent and extracted oil by using the control switch on the heating element. The control factor is the boiling point of the solvent (Migiro and Rivera, 1990), but the heat input to the flask continues throughout the extraction time, leading to a wide variation in temperature. During the extraction process the temperature of the solvent increases beyond its boiling point (the so called extraction temperature) due to presence of the extracted oil (boiling point elevation).

\section{Oil yield and other parameters}

Table 2 summarizes the parameters studied in this work.

Table 2: Parameters used for studying the effect of particle size on vegetable oil extraction process

\begin{tabular}{|c|c|c|}
\hline Parameter & Definition & Units \\
\hline$\Delta \mathbf{t}_{\mathrm{e}}$ & Extraction time interval & $\mathrm{h}$ \\
\hline $\mathbf{M}_{\text {or }}$ & Mass of oil recovered for the given extraction time interval & $\mathrm{kg}$ \\
\hline $\mathbf{E}_{\mathbf{r}}$ & $\begin{array}{l}\text { Rate of extraction (kg oil recovered/extraction time) } \\
\qquad \mathrm{M}_{\mathrm{or}} / \Delta \mathrm{t}_{\mathrm{e}}\end{array}$ & $\mathrm{kg} / \mathrm{h}$ \\
\hline $\mathbf{M}_{\mathrm{SL}}$ & Mass of solvent lost during extraction & $\mathrm{kg}$ \\
\hline $\mathbf{R}_{\mathrm{LO}}$ & $\begin{array}{l}\text { Ratio of kg solvent lost to kg oil recovered } \\
\qquad=\mathrm{M}_{\mathrm{SL}} / \mathrm{M}_{\mathrm{or}}\end{array}$ & $\mathrm{kg} / \mathrm{kg}$ \\
\hline $\mathbf{R}_{\mathrm{LS}}$ & $\begin{array}{c}\text { Rate of solvent loss (kg solvent lost/extraction time) } \\
=\mathrm{M}_{\mathrm{SL}} / \Delta \mathrm{t}_{\mathrm{e}}\end{array}$ & $\mathrm{kg} / \mathrm{h}$ \\
\hline $\mathbf{M}_{\mathrm{vc}}$ & Mass of volatile compounds driven off during extraction & $\mathrm{kg}$ \\
\hline $\mathbf{R}_{\mathrm{ov}}$ & $\begin{array}{l}\text { Ratio of the } \mathrm{kg} \text { oil recovered to the kg volatile compounds } \\
\text { driven off } \\
\qquad=\mathrm{M}_{\mathrm{or}} / \mathrm{M}_{\mathrm{vc}}\end{array}$ & $\mathrm{kg} / \mathrm{kg}$ \\
\hline $\mathbf{M}_{\mathrm{sf}}$ & Mass of solvent fed into the flask & $\mathrm{kg}$ \\
\hline $\mathbf{R}_{\mathrm{s}}$ & $\begin{array}{l}\text { Ratio of the kg oil recovered to kg solvent used } \\
\qquad \mathrm{M}_{\mathrm{or}} / \mathrm{M}_{\mathrm{sf}}\end{array}$ & $\mathrm{kg} / \mathrm{kg}$ \\
\hline $\mathbf{M}_{\mathrm{sr}}$ & Mass of solvent recovered & $\mathrm{kg}$ \\
\hline$S_{\text {rec }}$ & $\begin{array}{l}\text { Percent of the solvent recovered } \\
\qquad=\left(\mathrm{M}_{\mathrm{sr}} / \mathrm{M}_{\mathrm{sf}}\right) \times 100 \%\end{array}$ & $\%$ \\
\hline $\mathbf{M}_{\mathrm{sa}}$ & Mass of sample used & $\mathrm{kg}$ \\
\hline $\mathbf{Y}_{1}$ & $\begin{array}{r}\text { Oil yield based on total mass of the sample } \\
\qquad\left(\mathrm{M}_{\mathrm{or}} / \mathrm{M}_{\mathrm{sa}}\right) \times 100 \%\end{array}$ & $\%$ \\
\hline
\end{tabular}

\section{Methodology}

\section{The experimental facility}

The extraction process was carried out in the soxhlet extractor, as shown in Figure $1^{2}$. This equipment is used for extraction of various compounds such as oils from various sources, e.g. seeds, leaves, stems, etc. The unit can also be used for extraction of active components from various plants provided the right solvent is used.

\footnotetext{
${ }^{2}$ http://en.wikipedia.org/wiki/Image:
} Soxhlet_extractor.png 


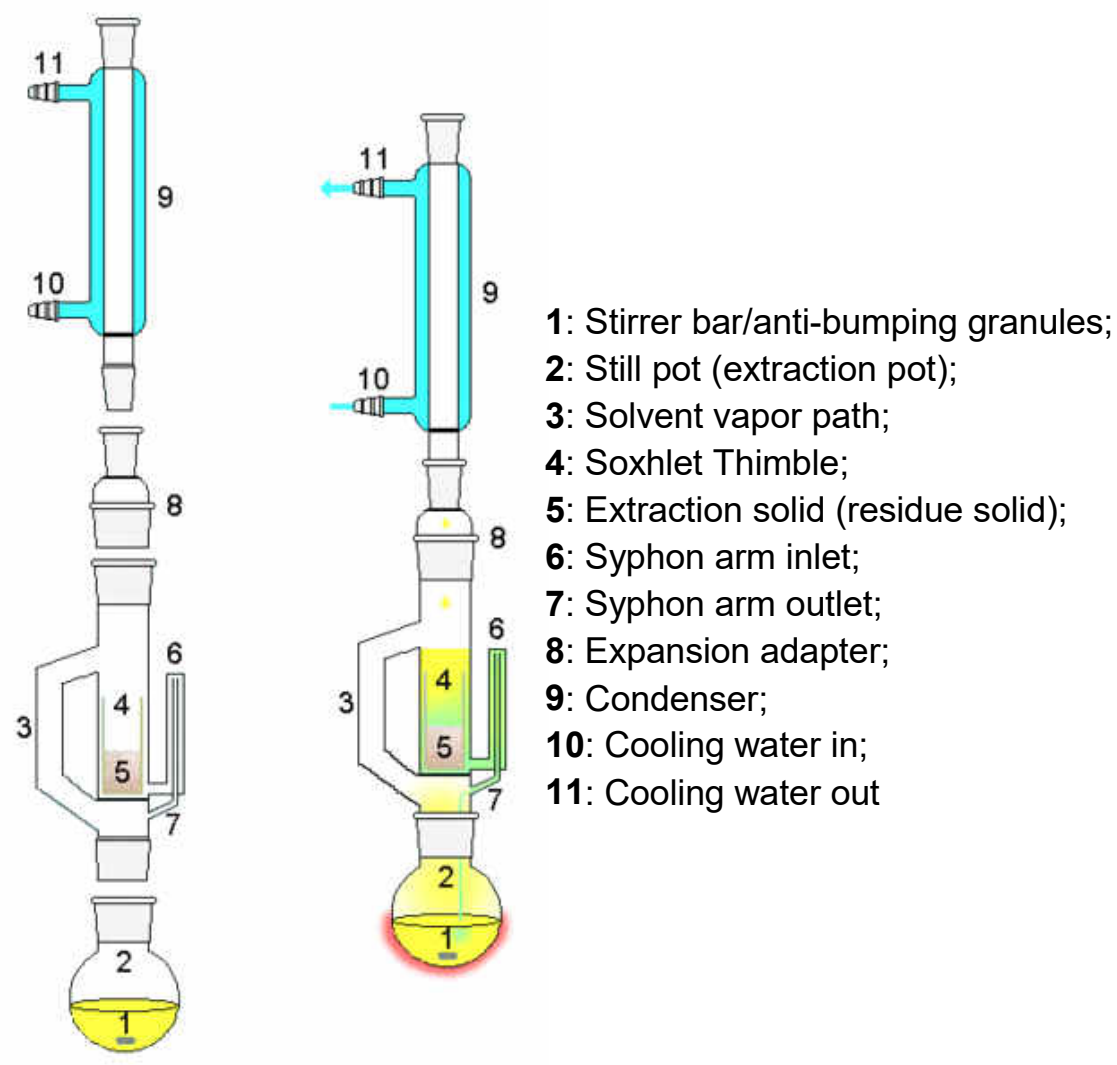

Figure 1: Schematic of soxhlet extractor equipment

The extractor contains mainly three parts: the flask containing the solvent, the holder, and the condenser. The sample to be processed is placed in the thimble, and covered with cotton wool. A known volume of the solvent is placed in the flask, usually 150-200 $\mathrm{ml}$. The solvent chosen must have a boiling point well below that of water, to avoid too much water in the extract. However, the water is removed from the extract during solvent recovery. When the flask is heated beyond the boiling point of the solvent, the solvent evaporates and the condensate drops into the sample. As the solvent passes through the sample, the oil to be extracted dissolves into the solvent vapor and is collected down into the flask, after condensation as the two passes into the condenser. The condenser is usually connected to the cooling water, which circulates within the coil for a short residence time. The extractor can take up to six samples at a time. However, due to large solvent consumption, only five samples were tested grouping each run.

\section{Experimental procedures}

A known mass of the sample was placed in the thimble. A small portion of cotton wool of known mass was inserted into the thimble and the whole pack was weighed again. The mass of the empty dry flask was measured before pouring $200 \mathrm{ml}$ of n-hexane. The weight of the flask with its contents was again measured. This was followed by assembling the parts of the soxhlet extractor ready for extraction. The heaters were switched on to raise the temperature of the solvent. The extraction time was noted starting from the first bubbles of the solvent. The heaters were switched off after the extraction time is reached, after which the containers and the contents were allowed to cool. The thimble with its contents, the flask containing the extract and solvent, were again measured before transferring the flask to the rotor-vapor for oil recovery. The flask containing the oil was placed into the oven set at $105 \pm 5^{\circ} \mathrm{C}$ to remove any moisture. After 1 hour, the flask containing the extracted oil was measured and recorded.

\section{Experimental design}

Experiments were carried out using, n-hexane as a solvent. The ratio of $\mathrm{kg}$ solvent per $\mathrm{kg}$ ground seeds 
was varied between 4.0 to $5.0 \mathrm{~kg} / \mathrm{kg}$. Although this parameter affects the yield of oil it could not be varied widely due to limitation of the volume of solvent container, which can only take about $120-$ $150 \mathrm{ml}$. The thimble capacity was limited to only 30 $\mathrm{g}$ of sample.

Five different particle sizes were used in this study, the average sizes were $0.25,0.75,1.3,3.3$, and 7.5 $\mathrm{mm}$, based on standard sieves.

Six different extraction times were used to study the effect of extraction time, that is: $1,2,3,4,5$ and 8 hours. This is a measure of how long the sample is continuously subjected to the solvent at a constant temperature.

\section{Results and discussion}

\section{Oil yield}

The oil yield, $Y_{1}$ (based on the total mass of each sample) was studied at various particle sizes and extraction times, as shown in Figure 2. Ranging from 10 to $60 \%$, the oil yield decreased with increasing particle size for all extraction times. For particle sizes up to $1.3 \mathrm{~mm}$, the oil yield was the highest. Beyond this size the oil yield decreased abruptly.

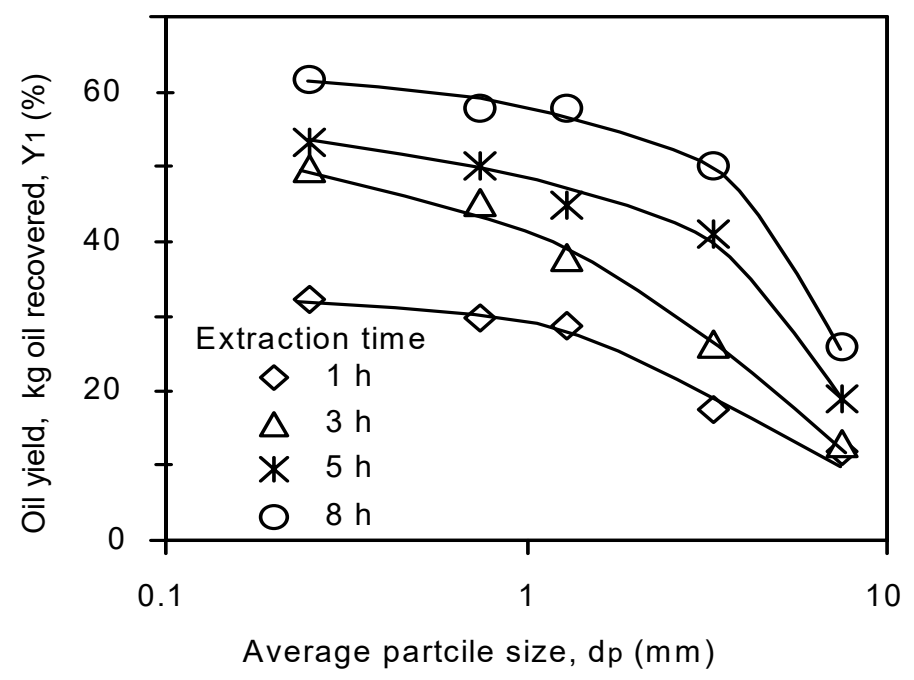

Figure 2: Variation of the oil yield with the average particles size for different extraction times

\section{Rate of extraction}

The rate of extraction, $E_{r}$, is very much dependent on the particle size and extraction time, as shown in Figure 3. For large particle sizes, $\mathrm{d}_{\mathrm{p}}>1.33 \mathrm{~mm}$, the observed values of $E_{r}$ were the lowest. This can be attributed to reduced intrinsic capacity for diffusion of solvent and oil.

Figure 3 shows that higher values of $\Delta t_{e}$ lead to decreased $E_{r}$ values as observed for extraction times of 3 to 8 hours. This is because, longer extraction times are affected by equilibrium phenomena, such that, as time is extended, the equilibrium between solvent and oil is approached and hence, the solvent can no longer dissolve more oil (Rodligues et al., 2005). Meanwhile the oil in the seed particle is already exhausted at higher $\Delta \mathrm{t}_{\mathrm{e}}$ values, leading to decreased $E_{\mathrm{r}}$ as reported also by Rivera and Migiro (1990). At extended extraction time, the viscosity of the solvent is higher due to presence of fats, oil and other volatile compounds, and its flow through the cake and through the rest of the equipment is hindered leading to decreased extraction rates. 


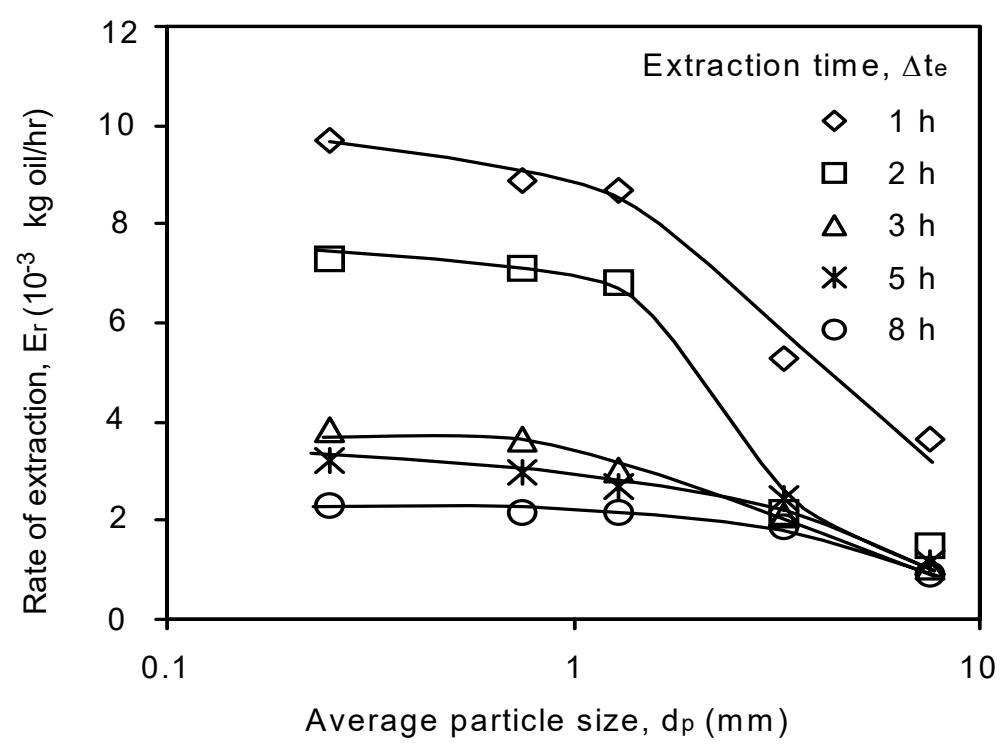

Figure 3: Variation of extraction rate with particle size

\section{Amount of solvent used}

The solvent requirement during extraction is a critical cost element especially in large scale processes. In this study, $\mathrm{R}_{\mathrm{S}}$ was studied for different extraction times and average particle sizes as shown in Figure 4. Different from Figure 3, Figure 4 shows that the values of $R_{s}$ are highest at extended extraction time of $8 \mathrm{~h}$ than at shorter extraction times because of the solvent recycle.
In general, $R_{s}$ should increase for higher profit in vegetable oil processing. Higher values of $R_{s}$ were observed for small particle sizes, $d_{p}<3.3$ $\mathrm{mm}$, which decreased beyond this particle size. Also, large particle size leads to lower values of $\mathrm{R}_{\mathrm{s}}$. Extending extraction times from 1 to 8 hours lead to higher values of $R_{s}$ because the solvent is recycled many times during the process. The observed values of $R_{s}$ were higher than the literature values reported for supercritical $\mathrm{CO}_{2}$ oil extraction (Araújo et al., 2000).

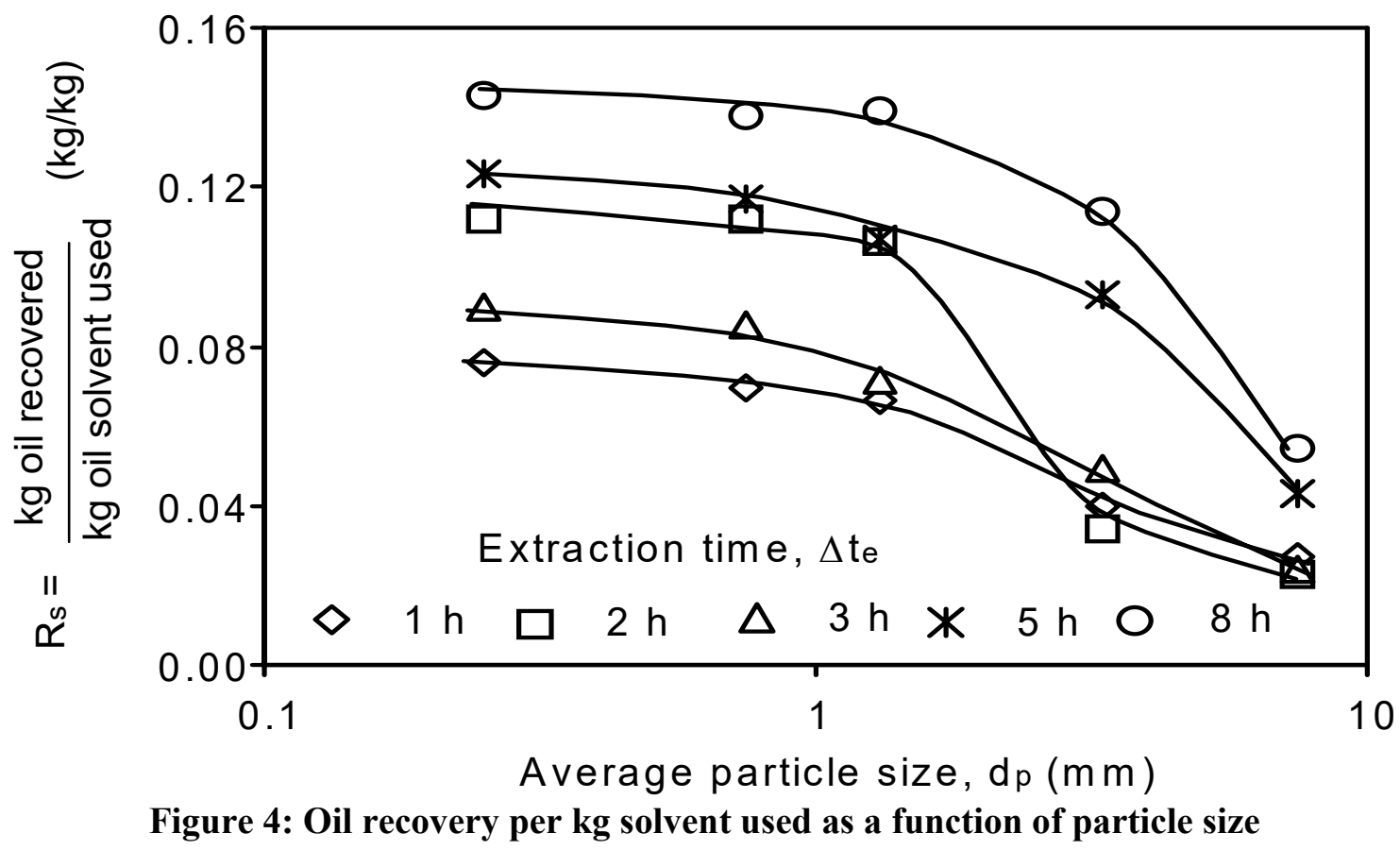


Volatile compounds driven off during solvent extraction

During solvent extraction, most of the volatile compounds in the seeds are also driven off together with the oil, leaving the dry cake behind, and also contributing to contamination of the product. The fraction of volatile matter driven off from the seeds reached up to $43 \%$ of the total mass as shown in Figure 5. Large quantities of volatile compounds were driven off from smaller compared to larger particle sizes, that is, for $d_{p}$ ranging between 0.75 and $1.33 \mathrm{~mm}$. For $\mathrm{d}_{\mathrm{p}}>1.33 \mathrm{~mm}$, there was a sharp decrease in the quantity of volatile compounds driven off.

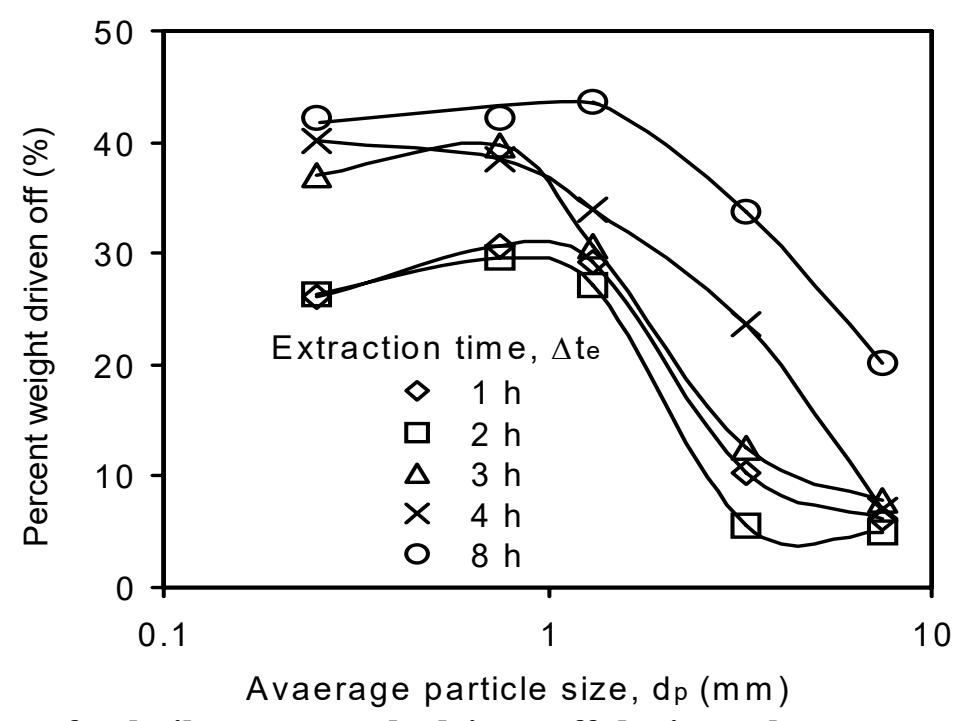

Figure 5: Quantity of volatile compounds driven off during solvent extraction as function of particle size

Oil is part of the compounds driven off from the seed particles during solvent extraction, which dissolves in the solvent and later on deposited in the flask. The ratio of mass of oil extracted to the total mass of volatile compounds driven off, $R_{o v}$, is plotted versus the average particle size, $d_{p}$, for different extraction time intervals in Figure 6.

The values of $R_{o v}$ ranged between 0.5 and 2.5 $\mathrm{kg} / \mathrm{kg}$. Initially, at low particle sizes $\left(\mathrm{d}_{\mathrm{p}}<1.33 \mathrm{~mm}\right)$ the $R_{o v}$ was observed to be relatively constant depending on the extraction time, but increased abruptly for $d_{p}>1.33 \mathrm{~mm}$. Highest values of $R_{o v}$ were observed at extraction time of $2 \mathrm{~h}$. For $\Delta \mathrm{t}_{\mathrm{e}}=8$ $h$, all the values of $R_{o v}$ were less than unity, signifying that less oil was recovered than other materials driven off.

Figure 6 shows also that for larger particle sizes, in particular $3.3 \mathrm{~mm}$, the values of Rov were the highest for all extraction times. That is, more oil was recovered at $d_{p}=3.3 \mathrm{~mm}$ compared to other particle sizes. In other words, most of the driven off compounds comprise of oils except few cases where the ratio is less than unity (indicating that less oil was recovered compared to the total volatile compounds). In terms of oil purity, the size with higher Rov value will give purer samples of extracted oil, than those with lower Rov value. 


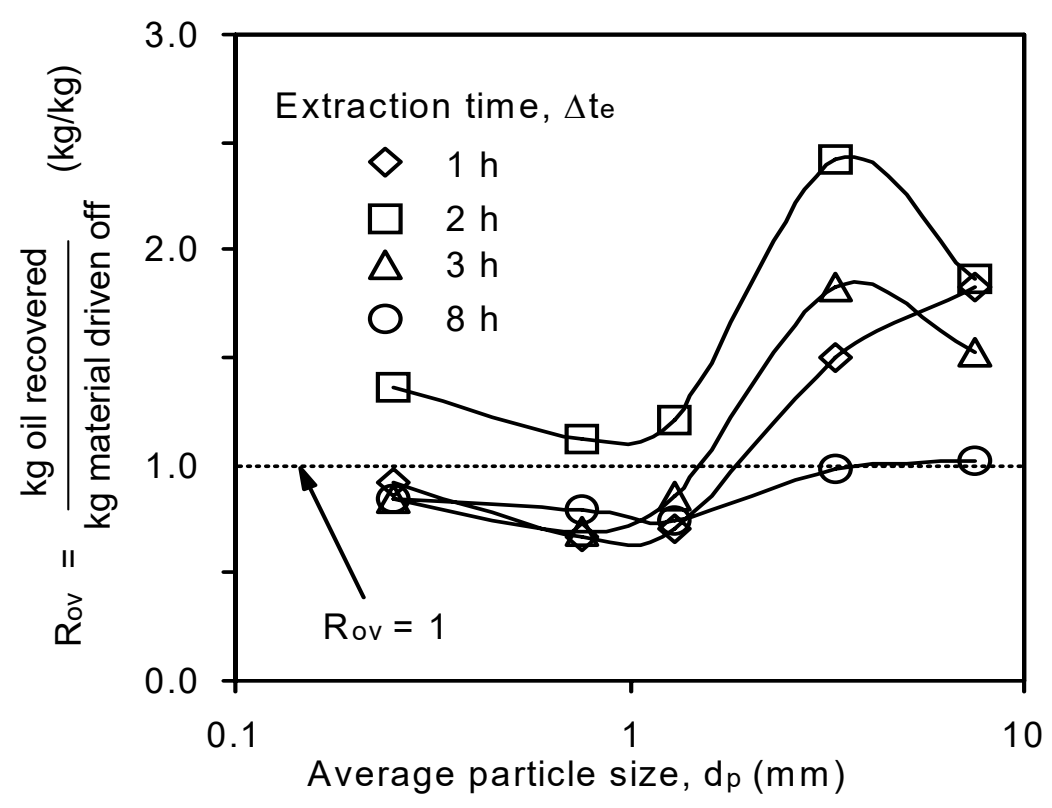

Figure 6: The ratio of oil recovered to the volatile compounds driven off as function of particle size

\section{Solvent recovery}

It is more cost effective to recover the solvent during extraction, so that it can be reused as many times as possible. The values of percentage of solvent recovered, $S_{\text {rec }}$, at various extraction times and particle sizes are shown in Figure 7. Longer extraction time (for instance $8 \mathrm{~h}$ ) leads to low percent recovery of solvent than shorter time (1 hour). Low values of solvent recovery were observed at extended extraction times like $8 \mathrm{~h}$, indicating that more solvent is lost.
The solvent recovery ranged from 50 to $84 \%$ which is lower compared to the value and cost of the solvent used. It is important to extend this percent to $80-95 \%$. Higher values of solvent recovery were observed at higher particle sizes in particular 7.5 $\mathrm{mm}$. The loss of the solvent can be attributed to particle surface phenomena, such that small particles with larger surface area lead to higher loss of solvent, and vice versa.

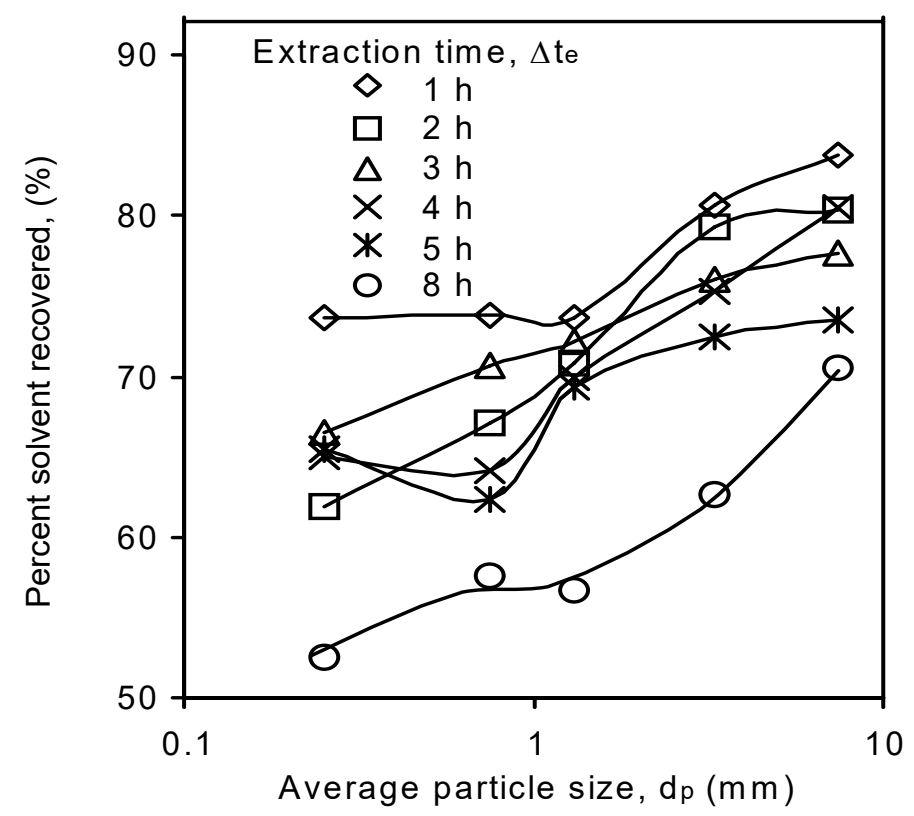

Figure 7: Variation of solvent recovered with particle size 


\section{Solvent loss}

The rate of solvent loss during extraction, $\mathrm{R}_{\mathrm{LS}}$, is an important parameter which can only be minimized if the data is available at different operating conditions. Figure 8 shows the variation of $R_{L S}$ with particle size for different extraction times.

The values of $R_{L S}$ decreased with increasing particle size, for all extraction times. The rate of solvent loss decreased also with increasing extraction time, such that lowest values of $\mathrm{R}_{\mathrm{LS}}$ were observed at $\Delta \mathrm{t}_{\mathrm{e}}=8 \mathrm{~h}$, while the highest values of $R_{L S}$ were observed at $\Delta t_{e}$ $=2 \mathrm{~h}$. Figure 9 shows the plots of $\mathrm{kg}$ solvent lost per $\mathrm{kg}$ oil recovered $\left(\mathrm{R}_{\mathrm{LO}}\right)$ for different operating conditions.
In this study, $\mathrm{R}_{\mathrm{LO}}$ values ranged between 0.5 and 2.0. The $R_{L O}$ values remained constant up to $d_{p}>$ $1.33 \mathrm{~mm}$, beyond which $\mathrm{R}_{\mathrm{LO}}$ increased abruptly. The operating range for solvent extraction is thus, $\mathrm{d}_{\mathrm{p}}<3.3 \mathrm{~mm}$, for which $\mathrm{R}_{\mathrm{LO}}<1.0$. The abrupt increase in solvent loss per $\mathrm{kg}$ oil recovered is due to the fact that very small amount of oil is recovered at $\mathrm{d}_{\mathrm{p}}=7.5 \mathrm{~mm}$, as shown in Figure 2, which corresponds to higher values of $\mathrm{R}_{\mathrm{LO}}$. The lost solvent combines with other volatile organic compounds released into the air as pollutants (USEPA, 2001b; 2002) and also as residue in the cake. Similarly, a ratio known as loss factor, expressed as volume of solvent per ton of oil recovered, was suggested by US-EPA (2001a).

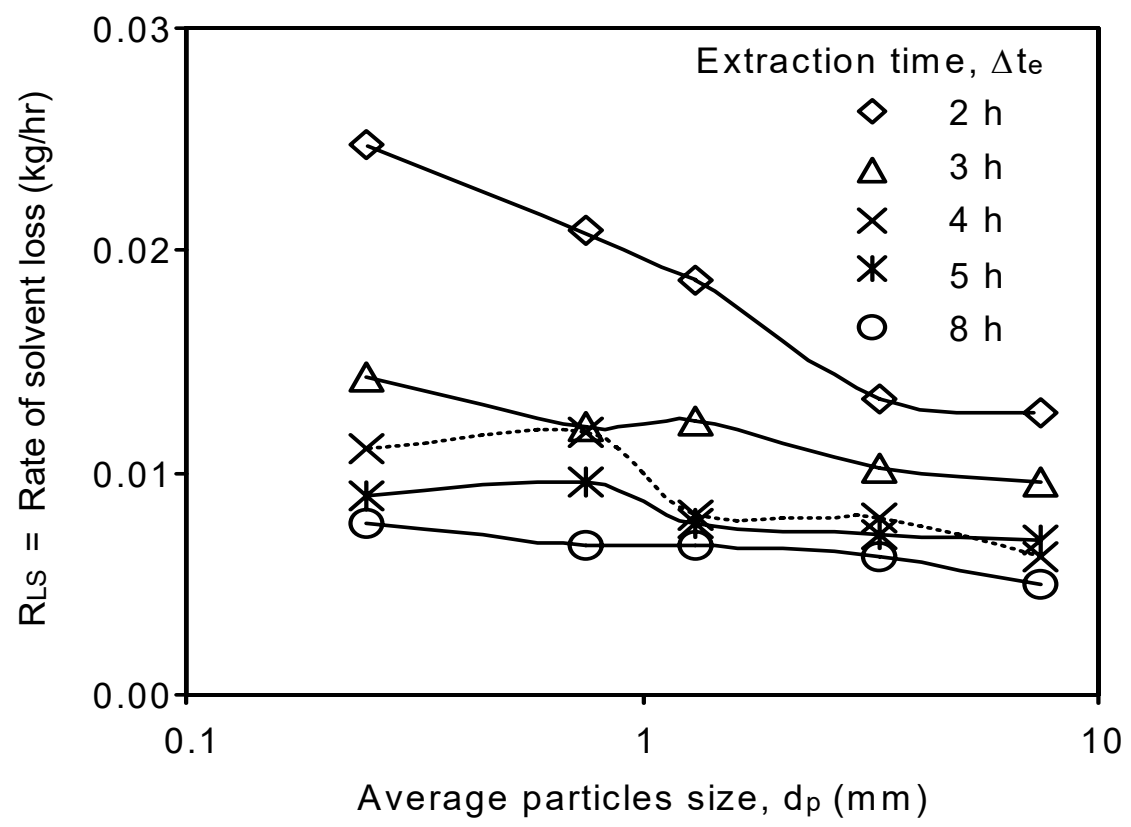

Figure 8: Variation of rate of solvent loss with particle size

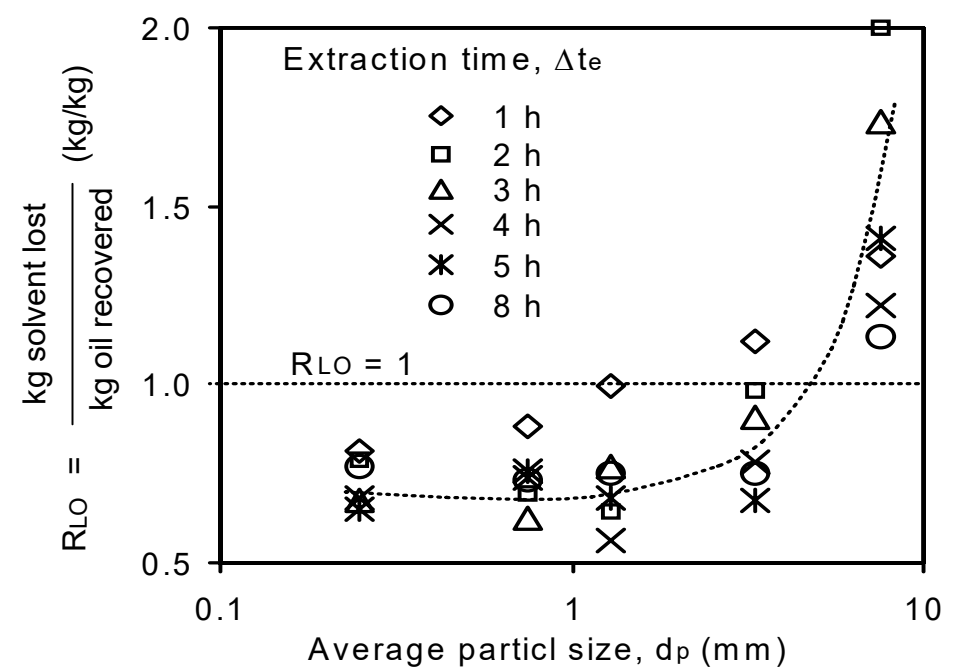

Figure 9: Ratios of solvent lost to oil recovered as a function of particle size 


\section{The overall effect of particle size}

Figure 10 presents the variation of the important vegetable oil extraction parameters (averaged over extraction time) as a function of the mean particle size.

The quantities $\mathrm{Y}_{1}$ (yield of oil), $\mathrm{R}_{\mathrm{s}}$ (the $\mathrm{kg}$ oil recovered/kg of solvent used), $\mathrm{E}_{\mathrm{r}}$ (rate of extraction, $\mathrm{kg}$ oil/ $\mathrm{h}$ ) and $\mathrm{R}_{\mathrm{LS}}$ ( $\mathrm{kg}$ solvent lost per hour) decreased with increasing particle size. On the other hand, $R_{o v}(\mathrm{~kg}$ oil yield per $\mathrm{kg}$ volatile matter driven off), $\mathrm{S}_{\text {rec }}$ (percent of solvent recovered) and $\mathrm{R}_{\mathrm{LO}}$ ( $\mathrm{kg}$ solvent lost $/ \mathrm{kg}$ oil recovered) increased with $d_{p}$, especially for $d_{p}>$ $0.75 \mathrm{~mm}$.

The trends shown in Figure 10 are averages of six values at extraction times of $1,2,3,4,5$, and 8 hours. Based on Figure 10, it cab be generalized that larger particle size above $1.3 \mathrm{~mm}$ increases the rate of solvent loss but decreases the oil yield, but the rate of solvent loss per unit time decreases at high particle sizes.

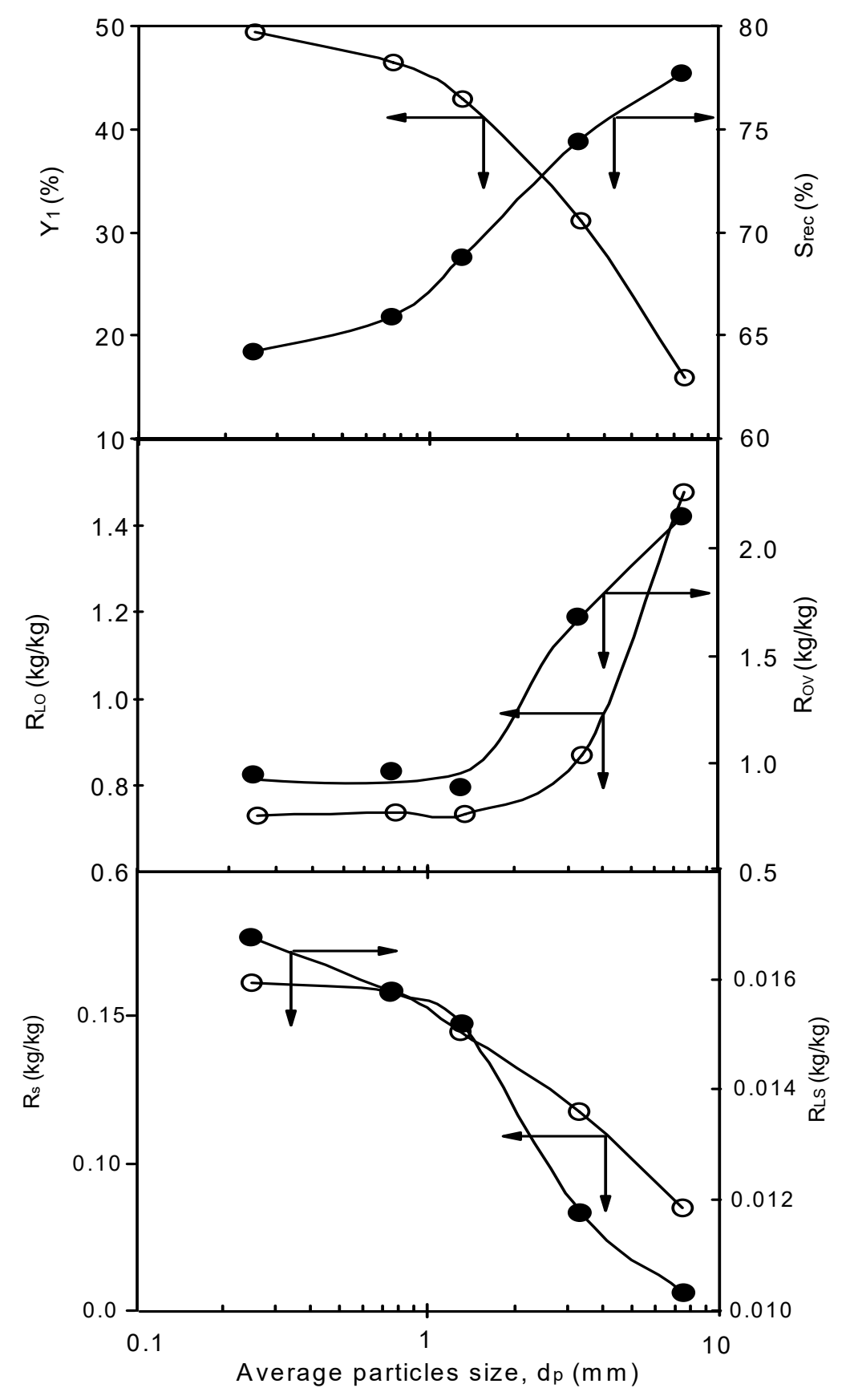

Figure 10: The overall effect of particle size on performance of solvent extraction 
Determination of optimum particle size

A score system was used to determine optimum particle size for solvent extraction. The averaged profiles were scaled between 0 and 1.0, using the following normalizing equation:

$$
X_{n}=\frac{X_{i}-X_{\min }}{X_{\max }-X_{\min }}
$$

A plot of the values of $X_{n}$ versus $d_{p}$ for different parameters is given in Figure 11.

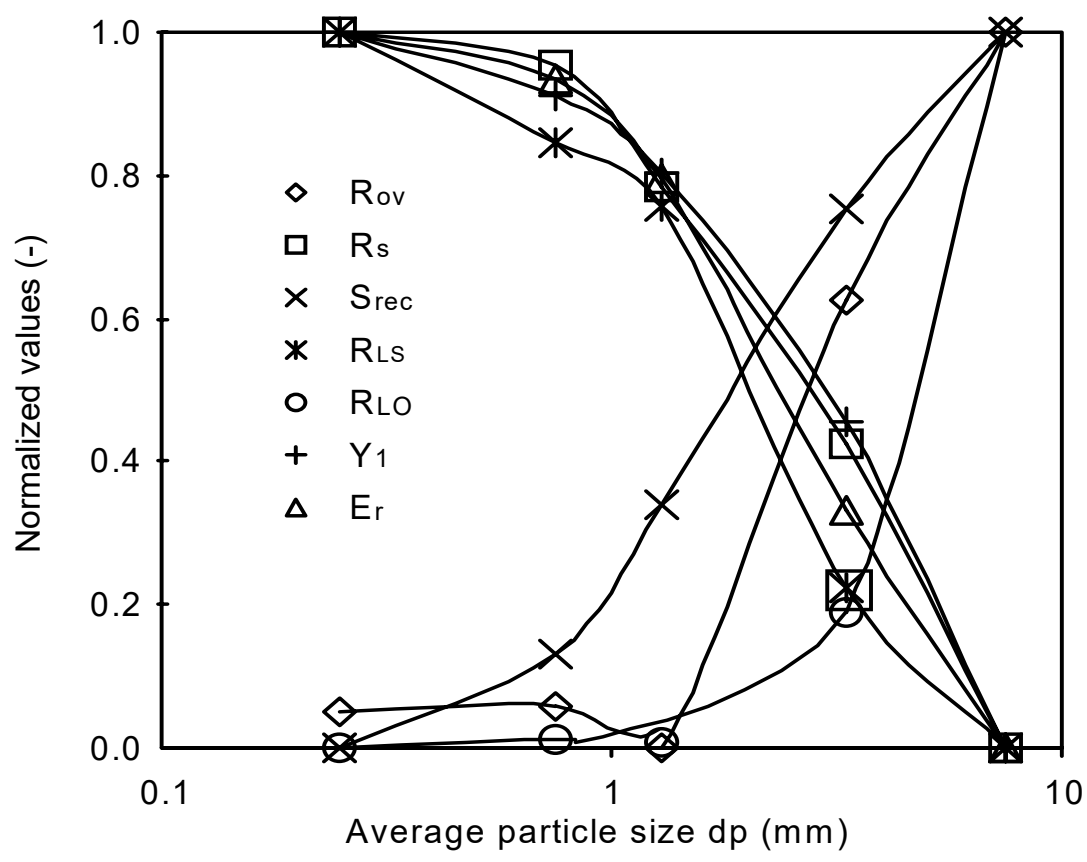

Figure 11: Effect of particles size on the performance of solvent extraction using normalized values

The normalized values were assigned a vertical vector whose magnitude equals the normalized value of the corresponding parameter, while the direction of the vector was coded as positive (upright) or negative (downward) depending on whether the parameter under test is a gain or loss in terms of the operation costs. This was done for all values of $d_{p}$ as shown in Table 3 . The rate of solvent loss and the $\mathrm{kg}$ solvent lost/kg oil recovered were given negative values while all other parameters were assigned positive signs. After assigning the negative or positive signs to the normalized values, the resulting values (or scores) for all particles sizes were summed up giving the sum of the scores, as summarized in Table 3.

Table 3 Sum of scores for particles sizes

\begin{tabular}{|l|c|c|c|c|c|}
\hline $\mathbf{d}_{\mathbf{p}}(\mathbf{m m})$ & $\mathbf{d}_{\mathbf{p}}=\mathbf{0 . 2 5}$ & $\mathbf{d p}=\mathbf{0 . 7 5}$ & $\mathbf{d}_{\mathbf{p}}=\mathbf{1 . 3}$ & $\mathbf{d}_{\mathbf{p}}=\mathbf{3 . 3}$ & $\mathbf{d}_{\mathbf{p}}=\mathbf{7 . 5}$ \\
\hline $\mathbf{R}_{\mathbf{o v}}$ & 0.05 & 0.06 & 0.00 & 0.63 & 1.00 \\
\hline $\mathbf{E}_{\mathbf{r}}$ & 1.00 & 0.94 & 0.80 & 0.33 & 0.00 \\
\hline $\mathbf{R}_{\mathbf{s}}$ & 1.00 & 0.96 & 0.78 & 0.43 & 0.00 \\
\hline $\mathbf{R}_{\mathbf{o v}}$ & 0.05 & 0.06 & 0.00 & 0.63 & 1.00 \\
\hline $\mathbf{S}_{\text {rec }}$ & 0.00 & 0.13 & 0.34 & 0.75 & 1.00 \\
\hline $\mathbf{R}_{\mathbf{L S}}$ & -1.00 & -0.85 & -0.76 & -0.22 & 0.00 \\
\hline $\mathbf{R}_{\mathbf{L O}}$ & 0.00 & -0.01 & -0.01 & -0.19 & -1.00 \\
\hline $\mathbf{Y}_{\mathbf{1}}$ & 1.00 & 0.91 & 0.80 & 0.46 & 0.00 \\
\hline Sum of scores & $\mathbf{2 . 1 0}$ & $\mathbf{2 . 1 9}$ & $\mathbf{1 . 9 6}$ & $\mathbf{2 . 8 1}$ & $\mathbf{2 . 0 0}$ \\
\hline
\end{tabular}


Based on the total scores for each particle size, presented in Figure 12, the optimum size was determined to be $3.3 \mathrm{~mm}$. The data shown in Figure

12 agrees with the fact that the size of the particles should not be too small, because the surface may not be so effectively used with a very fine material. Very fine material will impede circulation of the solvent and separation of the particles from the liquid and also drainage of the residue is made more difficult. For $d_{p}=7.5 \mathrm{~m}$, however, the sum of the scores drops again, which can be attributed to the fact that the particle size should not be too large as the distance through which the solvent must travel inside the particles increases.

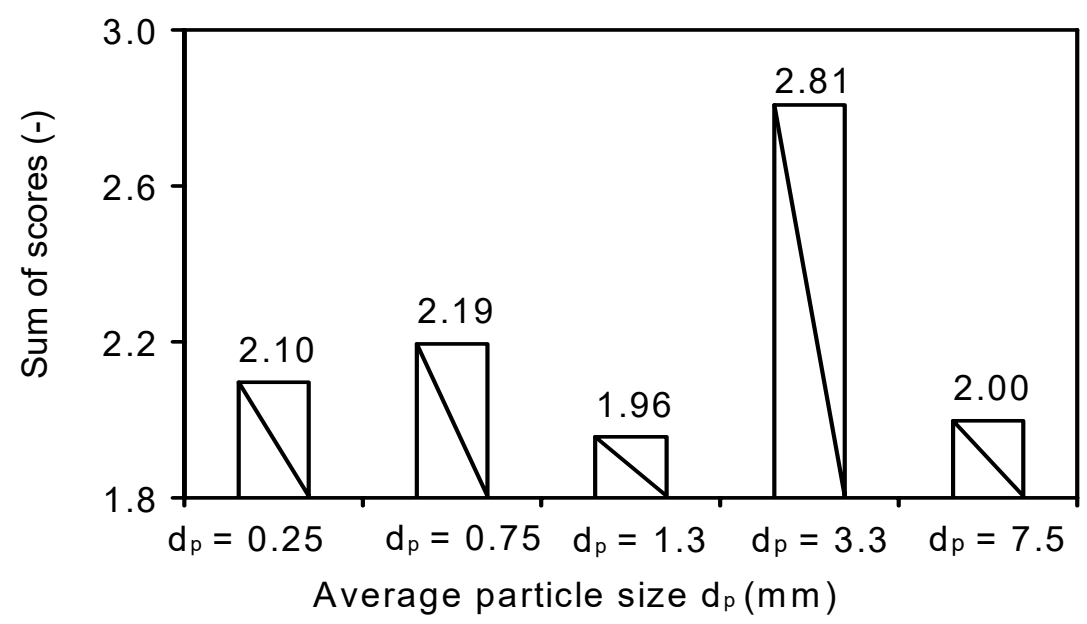

Figure 12: Sum of the scores for each particles size

\section{Conclusion}

Based on the results, it can be concluded that size reduction plays an important role on the oil yield and solvent management during the processing of oilseeds. In particular the following conclusion can be made:

(a) The oil yield from extraction and the amount of oil recovered per $\mathrm{kg}$ of solvent used decreases with increasing particle size.

(b) The amount of oil recovered per $\mathrm{kg}$ of volatile matter driven off increases with $d_{p}$ for $\mathrm{d}_{\mathrm{p}}>1.3 \mathrm{~mm}$, below which $\mathrm{R}_{\mathrm{ov}}$ remains constant.

(c) The percentage of solvent recovered increases with average particle size of the ground seeds.

(d) The rate of solvent loss per hour decreases with particle size.

(e) The quality of oil recovered per $\mathrm{kg}$ solvent lost increases with mean particle size, for $d_{p}>1.3$, otherwise remains constant for $d_{p}<$ $1.3 \mathrm{~mm}$.

(f) It was observed that the oil yield, oil recovered per $\mathrm{kg}$ solvent used, amount of solvent lost per unit of extraction time, and the rate of extraction ( $\mathrm{kg}$ oil per hour) decreased with increasing particle size.

(g) On the other hand, the percent of solvent recovered, the ratio of oil recovered to the total volatile matter driven off and the $\mathrm{kg}$ solvent lost per $\mathrm{kg}$ oil recovered, increased with increasing particle size.

(h) Based on the normalization of averaged extraction-parameters (averaged over extraction times), a $d_{p}=3.3 \mathrm{~mm}$ was observed to be the optimum size with highest sum of scores.

\section{References}

Assunçäo, F.P., Bentes, M.H.S., and Serruya, H., (1984), "A comparison of stability of oils from Brazil nut, Para rubber and Passion fruit seeds", J. Am. Oil Chem. Soc., 61, 1031-1036.

Cobb, W.Y., and Johnson, B.R., (1973), Physiochemical properties of peanut. In Peanuts: Culture and Uses. Amer. Peanut Res. \& Educ. Assoc. Stillwater, UK.

Elias, L.G., and Bressani, R., (1961). "The nutritive value of the Brazil nut oil", J. Am. Oil Chem. Soc., 1961, 38, 450-452.

FAO, (1994), Expert's recommendations on fats and oils in human nutrition. The article is adapted from the first chapter of fats and oils in human nutrition: report of joint expert consultation, FAO Food and Nutrition Paper No. 57. 
Jambunathan, R., (1991), Groundnut quality characteristics. Uses of tropical grain legumes. Proceedings of a consultants meeting 27-30 Mar 1989, ICRISAT Centre, India.

Misra, J.B., and Yadav, S.K., (1997). Arachilipometer-A simple device to determine oil content of groundnut seeds. Arachis News letter, ICRISAT, pp. 73-75.

Ratledge, C., and Boulton, C.A., (1985), "Fats and Oils", in M.Y. MooYoung (Ed.), "Comprehensive Biotechnology", Vol. 3, pp. 983-1003.

Reddy, P.S., (1988), “Groundnut”, Publication and Information Division, Indian Council of Agricultural Research, Krishi Anushandan Bhavan, Pusa, New Delhi.

Rivera, E.L., and Migiro, C.L.S., (1990), "Investigation on the use of Ethyl Acetate as Solvent for Seedoil Extraction", Tanzania J. of Science and Technology, 14(1), 73-83.
Rodligues, C.E.C., Silva, F.A., Marsaioli, A. Jr., and Meirelles, A.J.A., (2005), "Deacidification of Brazil nut and Macadamia nut oils by solvent extraction: Liquid-liquid equilibrium data at 298.2 K", J. Chem. Eng. Data, 50, 517-523.

US-EPA, (2001a), "Compliance Demonstration for the Solvent Extraction for Vegetable Oil Extraction NESHAP", EPA-453/B-04-001, September 2001.

US-EPA, (2001b), "Federal Register: National Emission Standards for Hazardous Air Pollutants (NESHAP): Solvent Extraction for Vegetable Oils Production", April 2001, pp. 19006-19026.

WHO, (World Health Organization) (1973), Technical report Series no. 522. Energy and protein requirements. Report of joint FAO/WHO Adhoc Expert Committee, WHO, Geneva. 